\title{
Development and Characterization of New Coating Material of Blended Epoxy-Lacquer with Aluminum
}

\author{
Xiaoxing Yan, ${ }^{1}$ Yunting Cai, ${ }^{1}$ Rong Lu, ${ }^{2}$ and Tetsuo Miyakoshi ${ }^{2}$ \\ ${ }^{1}$ College of Furniture and Industrial Design, Nanjing Forestry University, Nanjing 210037, China \\ ${ }^{2}$ Department of Industrial Chemistry, School of Science and Technology, Meiji University, 1-1-1 Higashi-Mita, Tama-ku, \\ Kawasaki-shi 214-8571, Japan \\ Correspondence should be addressed to Rong Lu; lurong@meiji.ac.jp
}

Received 23 February 2017; Accepted 8 May 2017; Published 31 May 2017

Academic Editor: De-Yi Wang

Copyright (C) 2017 Xiaoxing Yan et al. This is an open access article distributed under the Creative Commons Attribution License, which permits unrestricted use, distribution, and reproduction in any medium, provided the original work is properly cited.

\begin{abstract}
This study investigated the effects of aluminum (Al) mass fraction on the performance of an epoxy-lacquer based coating. The conductivity increased and IR emissivity and gloss decreased with increased $\mathrm{Al}$ mass fraction. When the $\mathrm{Al}$ mass fraction was decreased from $40 \%$ to $30 \%$, the adhesion and impact strength of epoxy-lacquer based coatings increased and were grade 1 and $50 \mathrm{Kg} \cdot \mathrm{cm}$, respectively. When the $\mathrm{Al}$ mass fraction was decreased to $10 \%$, the mechanical properties of epoxy-lacquer based coatings decreased. Potentiodynamic polarization and electrochemical impedance spectroscopy of coatings showed that epoxy-lacquer based coating with $30 \% \mathrm{Al}$ mass fraction has the best corrosion resistance and the lowest porosity. The epoxy-lacquer based coating with the best stability was that of $30 \% \mathrm{Al}$ mass fraction. Comparing epoxy-lacquer based coating with polyurethane based coating, the epoxy-lacquer based coating presents not only lower emissivity and gloss but also better mechanical properties and corrosion resistance.
\end{abstract}

\section{Introduction}

Applications of low infrared (IR) emissivity coatings (LIREC) [1] in the civil, aero, and military fields have received much attention [2]. In recent years, researchers have conducted extensive work on several LIREC, such as $\mathrm{La}_{0.67} \mathrm{Ca}_{033-x} \mathrm{Sr}_{x} \mathrm{MnO}_{3}$ compounds [3], ceramic composite [4], indium tin oxide composites [5], organic/inorganic composite coatings [6], and silver and aluminum (Al) [7]. In particular, the application of $\mathrm{Al}$ filler to LIREC has practical application potential [8].

Gloss is one of the important criteria for evaluating the quality of coatings. In fact, gloss is a complex phenomenon caused by the interaction between the light and the coating surface [9]. High gloss of polyurethane (PU)/Al leads to incompatibility between visible light and near infrared light. Tan et al. [10] and $\mathrm{Wu}$ and $\mathrm{Yu}$ [11] studied the effects of modified $\mathrm{Al}$ on the gloss and IR emissivity. However, these methods mainly concentrated on the effects of modified filler on LIREC. An organic adhesive is an important component of organic/inorganic composite coatings, but little work has been published which quantifies the effect of an organic adhesive on the gloss of LIREC.

Not only should LIREC have low IR emissivity, but also they should have good durability and mechanical properties suitable for practical application [12]. It is still a challenge to prepare low IR emissivity coatings with high corrosion resistance and mechanical properties today [11]. Although many synthetic polymers such as PU have been widely used as organic adhesives of low IR emissivity coatings, they show low mechanical properties and low corrosion resistance; therefore, developing natural products is still a very attractive solution for environmental protection purposes [13]. Raw lacquer [14] is a natural coating material that has excellent properties such as environmental friendliness, high durability, and corrosion resistance, and it has been widely used in areas such as chemical, textile, industrial, shipbuilding, mechanical, and electrical products [15]. However, the high price of raw lacquer and poor adhesion of lacquer to metal substrates have limited its application in low IR emissivity 
coatings. Modification of lacquer with epoxy (epoxy-lacquer) not only reduces the cost of raw lacquer but also improves the adhesion of the lacquer coating [16].

In this study, LIREC were obtained by adding the epoxylacquer as an organic adhesive. The effects of $\mathrm{Al}$ mass fraction on the performance of the epoxy-lacquer based coatings were investigated, and the epoxy-lacquer based coating was compared to PU based coatings.

\section{Experimental}

2.1. Materials. Al powder flakes with a particle size $\sim 10 \mu \mathrm{m}$ and a silane coupling agent (KH560) were supplied by Beijing Fengean Science Ltd. Co. Epoxy-lacquer (T09-17, epoxylacquer $=3: 4$ ) was supplied by the Xian Raw Lacquer and Coating Research Institute of China.

2.2. Preparation of Epoxy-Lacquer Based Coating. Firstly, sandpaper was used to polish the tinplate substrate, oil was removed using gasoline, and then the substrate was dried in an oven. The epoxy-lacquer and $\mathrm{Al}$ powder were mixed, and the $\mathrm{Al}$ mass fraction was controlled at $40 \%, 30 \%, 20 \%$, or $10 \%$. Then KH560 (2.0\%) was added to the mixture as an organic surface treatment to improve the dispersion for the Al powder in the epoxy-lacquer [17]. Second, the mixture was blended uniformly by an ultrasonic mixer for $10 \mathrm{~min}$ and then sprayed on the tinplate substrate. Finally, the epoxy-lacquer based coating was gotten after $24 \mathrm{~h}$ placed in room temperature. The thickness of the epoxy-lacquer based coating was about $40 \mu \mathrm{m}$ after drying.

2.3. Characterization. The IR emissivity in the range of 8-14 $\mu \mathrm{m}$ of epoxy-lacquer based coating was tested in an IR2 double wave IR radiometer (Shanghai Institute of Technological Physics of the Chinese Academy of Sciences). The conductivity of the epoxy-lacquer based coating was tested on a Keithley 6514 four-point probe conductivity device. The microstructure of epoxy-lacquer based coatings was observed by scanning electron microscope (SEM) (SX-40). Fourier transform infrared (FT-IR) spectrometry of epoxylacquer based coatings was performed by a VERTEX $80 \mathrm{~V}$ infrared spectrometer. A WGG gloss meter (Tianjin Test Equipment, China) was used to observe the gloss of epoxylacquer based coatings. The adhesion of the epoxy-lacquer based coatings was tested by a QFZ-II circular cutting instrument (Tianjin Test Equipment) according to the Standardization Administration of China GB 1720-79 (89), and the impact resistance of the epoxy-lacquer based coatings was measured with an impactor based on the Standardization Administration of China GB/T 1732-93, respectively. The roughness of the epoxy-lacquer based coatings was measured by a JB-4C roughness meter (Shanghai Taiming Optical Instrument, China).

The coatings were placed in a deionized $\mathrm{NaCl}$ water solution $(3.5 \% \mathrm{NaCl}, \mathrm{pH}$ 7) that had been purified by argon for $1 \mathrm{~h}$ in an electrochemical workstation CHI750C to carry out a polarization test and electrochemical impedance spectroscopy (EIS) measurements under normal temperature conditions [18]. A saturated calomel electrode and a platinum
TABLE 1: IR emissivity of different $\mathrm{Al}$ mass fraction.

\begin{tabular}{lc}
\hline Al mass fraction (\%) & IR emissivity \\
\hline 40 & 0.032 \\
30 & 0.065 \\
20 & 0.479 \\
10 & 0.796 \\
\hline
\end{tabular}

plate were as the reference electrode and counter electrode, respectively, which were exposed to a corrosive environment. The rosin to paraffin ratio was $1: 1$, and they were mixed and heated to $60^{\circ} \mathrm{C}$, coated on the edge of the epoxy-lacquer based coating. The exposed area was $\sim 1 \mathrm{~cm}^{2}$. Before the test, the coatings were soaked in $3.5 \% \mathrm{NaCl}$ solution for $30 \mathrm{~min}$, and the open circuit potential was determined until a constant value appeared. EIS of epoxy-lacquer based coating was performed in $3.5 \% \mathrm{NaCl}$ solution with the frequency range of $0.1 \mathrm{~Hz}$ to $100000 \mathrm{~Hz}$ using the amplitude of $5 \mathrm{mV}$. The Z-view software was used to analyze the EIS and the relative error of each element in the equivalent circuit was less than $5 \%$.

\section{Results and Discussion}

3.1. IR Emissivity. The relationship between IR emissivity of epoxy-lacquer based coatings and $\mathrm{Al}$ mass fraction is shown in Table 1. IR emissivity of epoxy-lacquer based coatings increased with the decrease of $\mathrm{Al}$ mass fraction. When $\mathrm{Al}$ mass fraction ranged between 30 and 40\%, IR emissivity of epoxy-lacquer based coatings was in the range of 0.032 to 0.065 . However, with decrease in the mass fraction of $\mathrm{Al}$ from $30 \%$ to $20 \%$, the IR emissivity of epoxy-lacquer based coatings proliferated from 0.065 to 0.479 . As can be seen from Table 1, lower Al mass fraction led to higher IR emissivity, and the reason will be analyzed below.

Under different Al mass fraction, the microstructure of the epoxy-lacquer based coatings was shown in Figure 1. Figure 1 shows that when the $\mathrm{Al}$ mass fraction was low (10\%), $\mathrm{Al}$ particles were distributed discretely in the epoxy-lacquer (Figure 1(a)). However, when the Al mass fraction was high $(30 \%)$, close contact between $\mathrm{Al}$ particles in epoxy-lacquer based coatings was observed (Figure 1(b)).

With a further increase of $\mathrm{Al}$ mass fraction in the coating, the roughness of epoxy-lacquer based coating increased (Figure 2), many agglomeration particles can be seen, and a smooth coating could not be obtained when the Al mass fraction was higher than $40 \%$; therefore, the Al mass fraction was increased no further for the preparation of coatings.

Basic principle of optics implies the relationship between the refractive index $(n)$ and conductivity $(\sigma)$ by the following formula [7]:

$$
n^{2}=\frac{\mu}{2}\left\{\left(\sqrt{\varepsilon^{2}+\frac{4 \sigma^{2}}{v^{2}}}\right)+\varepsilon\right\},
$$

where $\mu$ is magnetic conductivity, $\varepsilon$ is the dielectric constant, and $v$ is the Planck constant. According to formula (1), it can be inferred that high $\sigma$ can cause an increase of $n$. Reflectivity 

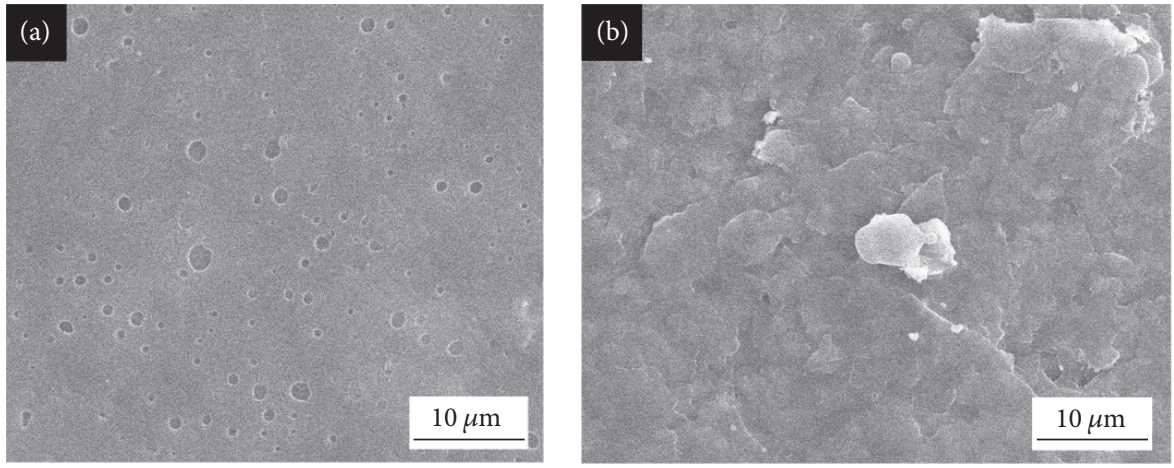

FIGURE 1: SEM of blended coating with (a) $10 \%$ and (b) $30 \%$ of Al.

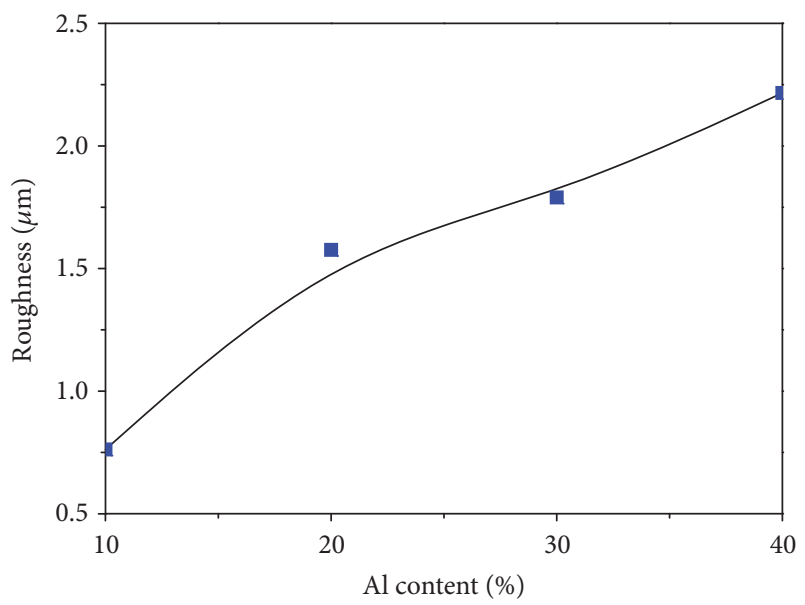

FIGURE 2: Roughness of coating with different Al mass fraction.

$\left(\rho_{e}\right)$ can be obtained through Kirchhoff's law by using the following formula [7]:

$$
\rho_{e}=\left(\frac{n-1}{n+1}\right)^{2}=\left(1-\frac{2}{n+1}\right)^{2}
$$

According to formula (2), it can be seen that high $n$ leads the increase of $\rho_{e}$. On the basis of the law of Kirchhoff and the law of conservation of energy, the relationship of IR emissivity and $\rho_{e}$ was the following formula $[7,19]$ :

$$
\text { IR emissivity }=1-\rho_{e} \text {. }
$$

Formulas (1)-(3) indicate that the higher conductivity can decrease IR emissivity. With an increase of Al mass fraction, the Al particles can come into closer contact and the coating's conductivity improved (Figure 3); therefore, the IR emissivity is reduced.

As Figure 4 shows, FT-IR of epoxy-lacquer based coating was related to $\mathrm{Al}$ mass fraction. The assignment of the peaks in spectra of epoxy-lacquer based coatings was shown in Table $2[20,21]$.

Figure 4 shows that the pure epoxy-lacquer coating had strong infrared absorption peaks; and increasing the mass fraction of $\mathrm{Al}$ from 0 to $40 \%$, the infrared peaks were weakened and even disappeared. Kirchhoff's law shows that, in

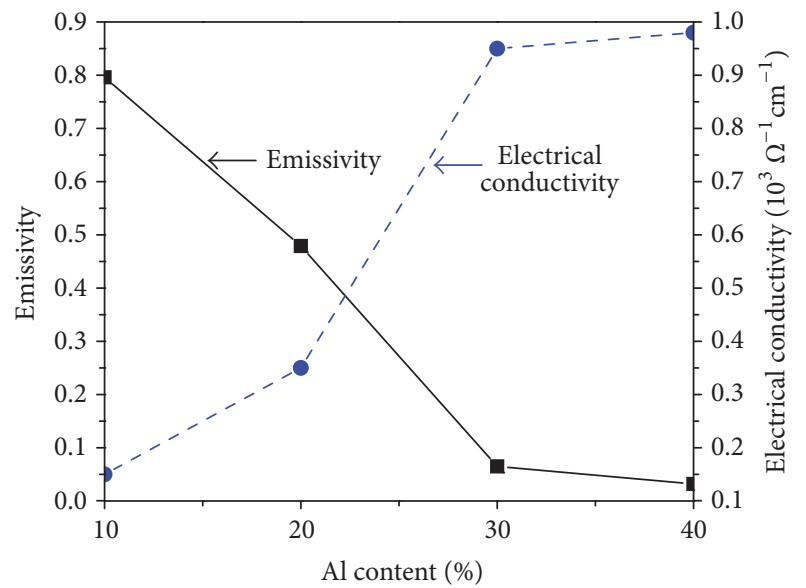

FIGURE 3: IR emissivity and conductivity changes with $\mathrm{Al}$ mass fraction.

TABLE 2: The assignment of peaks.

\begin{tabular}{ll}
\hline Peak $\left(\mathrm{cm}^{-1}\right)$ & Assignment \\
\hline 2920,2856 & Stretching vibration of C-H bond \\
1746 & Aldehyde groups \\
1620 & C=C bond vibration \\
1056 & C-O bond stretching vibration of chain \\
& ether \\
1102 & $\begin{array}{l}\text { C-O-C bond stretching vibration of the } \\
\text { open-chain ether } \\
\text { C-O-C stretching vibration of the } \\
\text { epoxide ring }\end{array}$ \\
\hline
\end{tabular}

the infrared equilibrium state, the infrared energy absorbed by the object is equal to the infrared energy emitted by the object. Therefore, according to Figure 4, with the increase of $\mathrm{Al}$ mass fraction, the IR emissivity of epoxy-lacquer based composite coating was reduced.

3.2. Gloss. Figure 5 showed the changes in the gloss of the epoxy-lacquer based coating with $\mathrm{Al}$ mass fraction. The gloss of the epoxy-lacquer based coatings increased rapidly from $4.8 \%$ to $51.7 \%$, while the mass fraction of $\mathrm{Al}$ was decreased 


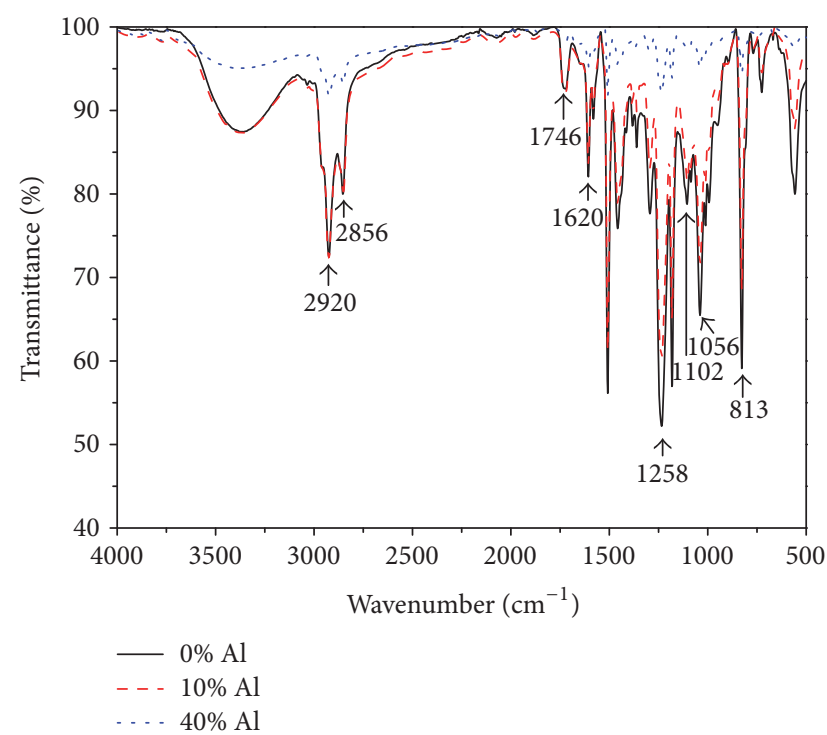

FIGURE 4: FT-IR of epoxy-lacquer based coating with different Al mass fraction.

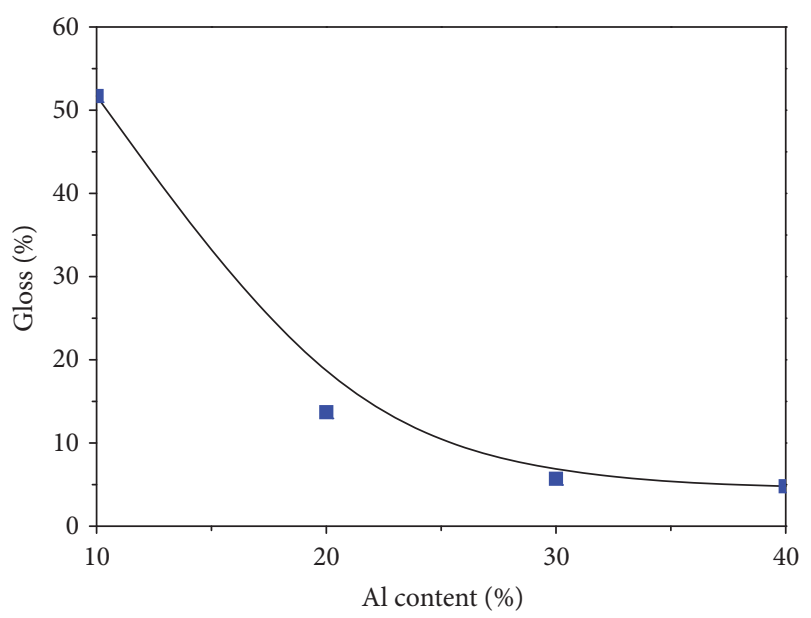

FIGURE 5: Gloss changes with different $\mathrm{Al}$ mass fraction.

from $40 \%$ to $10 \%$. The gloss of the epoxy-lacquer based coating was affected by the formulation, surface smoothness, refractive index, and other factors. With the decrease in $\mathrm{Al}$ mass fraction, the roughness of the coating decreased and the intensity of the reflected visible light increased, so that gloss increased. According to the specification for infrared camouflage coatings (GJB 1888-1994), when the detection angle is $60^{\circ}$, the gloss of the coating should be no more than $6 \%$ [10]. Figure 5 shows that when the $\mathrm{Al}$ mass fraction was more than $30 \%$, the gloss of coating was less than $6 \%$.

3.3. Mechanical Properties. The adhesion of the coating is the degree of coating attached to the substrate, and it is associated with the load that separates the coating and substrate completely. Figure 6 shows the adhesion curve of the epoxy-lacquer based coating with different $\mathrm{Al}$ mass fraction. According to Figure 6, the adhesion of epoxy-lacquer based

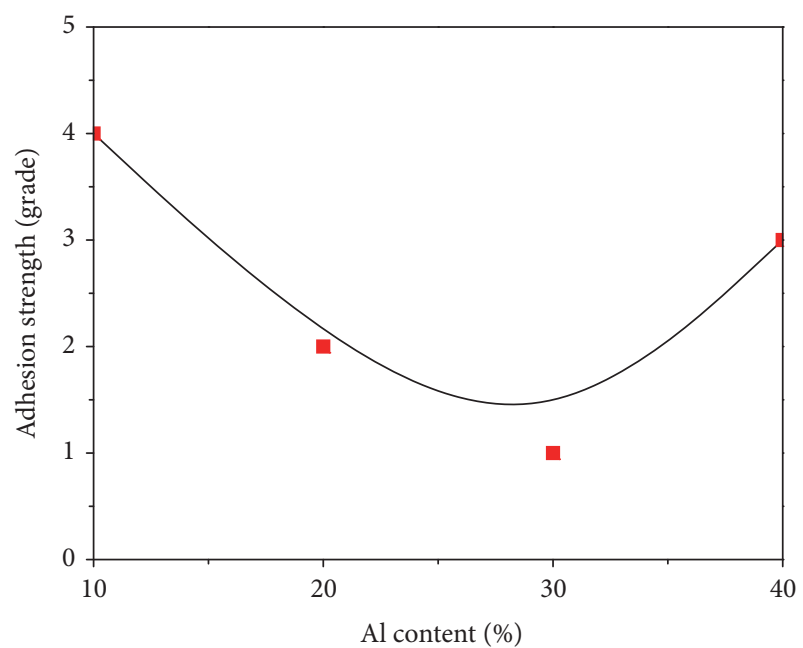

Figure 6: Adhesion with different Al mass fraction.

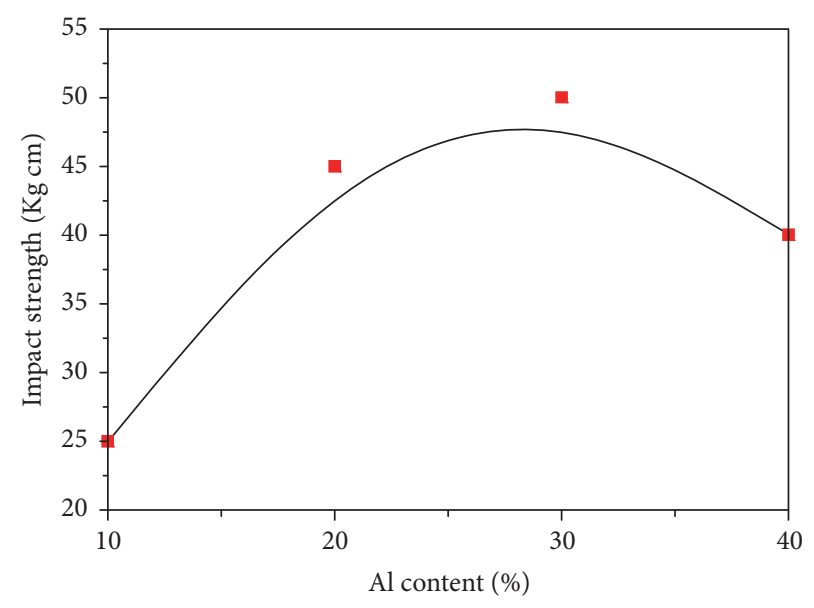

FIgURE 7: Impact strength changes with different $\mathrm{Al}$ mass fraction.

coating changed obviously with Al mass fraction. As shown in Figure 6, with increasing the Al mass fraction, the adhesion change presents a " $U$ " type. When the $\mathrm{Al}$ mass fraction was $40 \%$, the epoxy-lacquer based composite coating had poor adhesion of grade 3 due to the accumulation of filler which was difficult to disperse in the epoxy-lacquer. When the $\mathrm{Al}$ mass fraction was decreased from $40 \%$ to $30 \%$, the epoxylacquer based composite coating had good adhesion, mainly grade 1 due to the good dispersion of the Al filler particles (Figure 1(b)). However, when the $\mathrm{Al}$ mass fraction decreased from $30 \%$ to $10 \%$, the adhesion of the epoxy-lacquer based coating decreased from grade 1 to grade 4 . This is because the distribution of $\mathrm{Al}$ particles in the epoxy-lacquer changed from a continuous state to a discrete state with the increase of Al mass fraction (Figure 1), which led to a decrease in the cohesive strength and the mechanical interlock, thereby making the adhesion of the coating worse.

The change in impact resistance of the coating with different $\mathrm{Al}$ mass fraction was also studied in order to investigate the dynamic loading. Figure 7 illustrates the impact strength of the epoxy-lacquer based coating at different $\mathrm{Al}$ 
TABLE 3: Electrochemical corrosion results with different Al mass fraction.

\begin{tabular}{lcccccc}
\hline Mass fraction & $E_{\text {corr }}(\mathrm{V})$ & $R_{\mathrm{p}}\left(\Omega / \mathrm{cm}^{2}\right)$ & $I_{\text {corr }}\left(\mathrm{A} / \mathrm{cm}^{2}\right)$ & $\beta_{\mathrm{a}}(\mathrm{mV} / \mathrm{dec})$ & $\beta_{\mathrm{c}}(\mathrm{mV} / \mathrm{dec})$ & \multicolumn{1}{c}{${ }^{-6}$} \\
\hline Tinplate & -0.626 & $4.101 \times 10^{3}$ & $5.251 \times 10^{-6}$ & 191 & 226 & 236 \\
$40 \%$ & -0.368 & $3.070 \times 10^{7}$ & $1.635 \times 10^{-9}$ & 236 & 255 & $2.7 \times 10^{-7}$ \\
$30 \%$ & -0.189 & $7.729 \times 10^{7}$ & $6.899 \times 10^{-10}$ & 231 & 244 & $2.1 \times 10^{-6}$ \\
$20 \%$ & -0.292 & $3.476 \times 10^{7}$ & $1.486 \times 10^{-9}$ & 273 & $2.6 \times 10^{-4}$ \\
$10 \%$ & -0.617 & $1.416 \times 10^{7}$ & $3.780 \times 10^{-9}$ & & \\
\hline
\end{tabular}

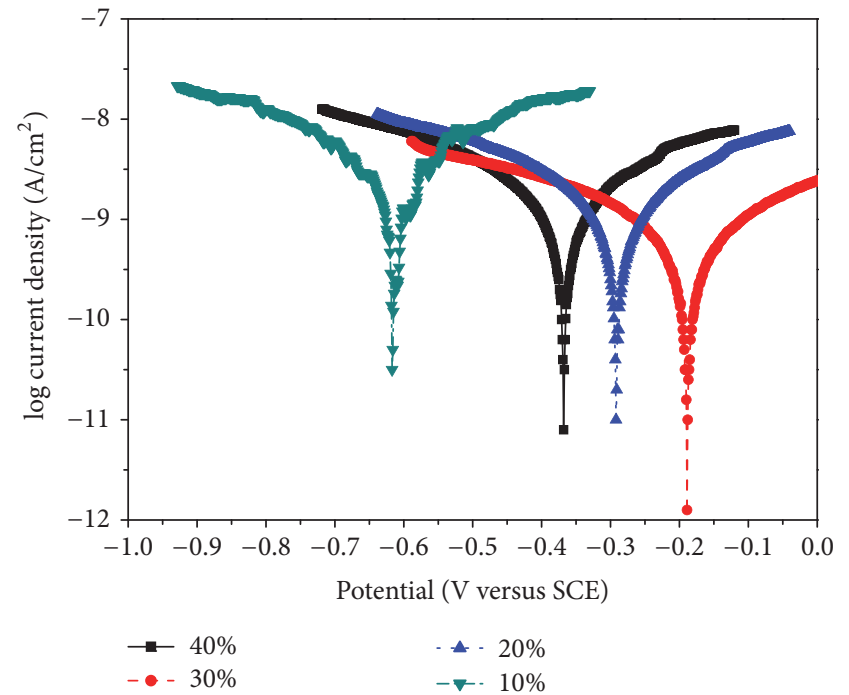

FIGURE 8: Polarization curves changes with different $\mathrm{Al}$ mass fraction.

mass fraction. With the decrease of the Al mass fraction from $40 \%$ to $30 \%$, the impact strength of the epoxy-lacquer based coating rose from $40 \mathrm{Kg} \cdot \mathrm{cm}$ to $50 \mathrm{Kg} \cdot \mathrm{cm}$. However, the impact strength of the coating decreased with the Al mass fraction decreasing from $30 \%$ to $10 \%$. A weak point of epoxylacquer is its high brittleness, which has poor ability to resist impact. The impact strength of the epoxy-lacquer based coating was affected by the $\mathrm{Al}$ mass fraction obviously: when the Al mass fraction was too high or too low, it cannot improve the impact strength performance. When $\mathrm{Al}$ particles are uniformly dispersed in the epoxy-lacquer, the impact strength of the epoxy-lacquer based coating is improved. The change of impact strength and adhesion of epoxy-lacquer based coating showed the same trend, implying that good adhesion could strengthen the impact resistance of the epoxy-lacquer based coating [22].

3.4. Corrosion Resistance. Potentiodynamic polarization is a method widely used in the laboratory to evaluate the durability of a coating. The durability of epoxy-lacquer based coatings was studied in $3.5 \%$ aqueous $\mathrm{NaCl}$ by corrosion. The better corrosion resistance, the higher durability. Figure 8 shows the potentiodynamic polarization curves of epoxylacquer based coatings with different $\mathrm{Al}$ mass fraction. Electrochemical parameters were calculated using the software of the electrochemical workstation CHI750C. The calculated results were summarized in Table $3 . E_{\text {corr }}$ is the corrosion potential, $I_{\text {corr }}$ is the corrosion current densities, $R_{\mathrm{P}}$ is the polarization resistance, and $\beta_{\mathrm{a}}$ and $\beta_{\mathrm{c}}$ are anode Tafel constant and cathode Tafel constant, respectively.

In general, when the corrosion potential is more positive, the polarization resistance is larger, and the corrosion current is lower, the coating has better anticorrosion properties. As shown in Table 3, when the $\mathrm{Al}$ mass fraction decreased from $40 \%$ to $30 \%, E_{\text {corr }}$ of the epoxy-lacquer based coating became more positive, $R_{\mathrm{P}}$ became higher, and $I_{\text {corr }}$ became lower, which indicated that epoxy-lacquer based coatings with $\mathrm{Al}$ mass fraction of $30 \%$ had better corrosion resistance than that of $40 \% \mathrm{Al}$ mass fraction. However, when the $\mathrm{Al}$ mass fraction decreased from $30 \%$ to $10 \%, E_{\text {corr }}$ of the epoxy-lacquer based coating became more negative, $R_{\mathrm{P}}$ became lower, and $I_{\text {corr }}$ became higher, which implied that the corrosion resistance properties of the epoxy-lacquer based coatings decreased with decreasing $\mathrm{Al}$ mass fraction from $30 \%$ to $10 \%$.

When the Al mass fraction is high, the coating becomes uneven, resulting in a lot of pores. The porosity of the coating has an important effect on corrosion resistance. The porosity $(P)$ of the epoxy-lacquer based coating can be calculated from the following formula [23]:

$$
P=\frac{R_{\mathrm{ps}}}{R_{\mathrm{pc}}} \times 10^{-\left(\Delta E_{\mathrm{corr}} / \beta_{\mathrm{at}}\right)} .
$$

In formula (4), $R_{\mathrm{ps}}$ and $R_{\mathrm{pc}}$ are the polarization resistance of the substrate and the coating coated substrate, respectively, $\Delta E_{\text {corr }}$ is corrosion potential difference between the epoxylacquer based coating and tinplate, and $\beta_{\text {at }}$ is the anode Tafel constant of the tinplate. The porosity of epoxy-lacquer based coatings with different $\mathrm{Al}$ mass fractions was calculated, as is shown Table 3. When Al mass fraction decreased from $40 \%$ to $30 \%$, the porosity of epoxy-lacquer based coatings decreased. The porosity value first decreased to the minimum of $2.7 \times 10^{-7}$ and then began to increase with the further decrease of Al mass fraction. With the decrease of the Al mass fraction from $40 \%$ to $30 \%$, the state of $\mathrm{Al}$ particles changed from aggregation to uniform distribution, which may lead to a denser coating structure and decrease the porosity, thereby decreasing the $\mathrm{NaCl}$ solution penetration and increasing the corrosion resistance [24]. When the $\mathrm{Al}$ mass fraction was decreased from $30 \%$ to $10 \%$, the morphology of the coating changed from the continuous particle contact state to the independent particle state, and thus the mixture was more loose (Figure 1). This made the epoxy-lacquer based coating 
TABLE 4: Impedance parameter values with different $\mathrm{Al}$ mass fraction.

\begin{tabular}{|c|c|c|c|c|}
\hline Mass fraction & $R_{\text {er }}\left(\Omega / \mathrm{cm}^{2}\right)$ & $R_{\mathrm{cp}}\left(\Omega / \mathrm{cm}^{2}\right)$ & $C_{\mathrm{c}}(\mathrm{F} / \mathrm{m})$ & $n$ \\
\hline $40 \%$ & 3.520 & $1.514 \times 10^{10}$ & $6.428 \times 10^{-3}$ & 0.30 \\
\hline $30 \%$ & 2.643 & $3.225 \times 10^{11}$ & $3.001 \times 10^{-3}$ & 0.32 \\
\hline $20 \%$ & 3.296 & $1.183 \times 10^{11}$ & $3.052 \times 10^{-3}$ & 0.33 \\
\hline $10 \%$ & 2.204 & $7.274 \times 10^{9}$ & $7.412 \times 10^{-3}$ & 0.27 \\
\hline
\end{tabular}

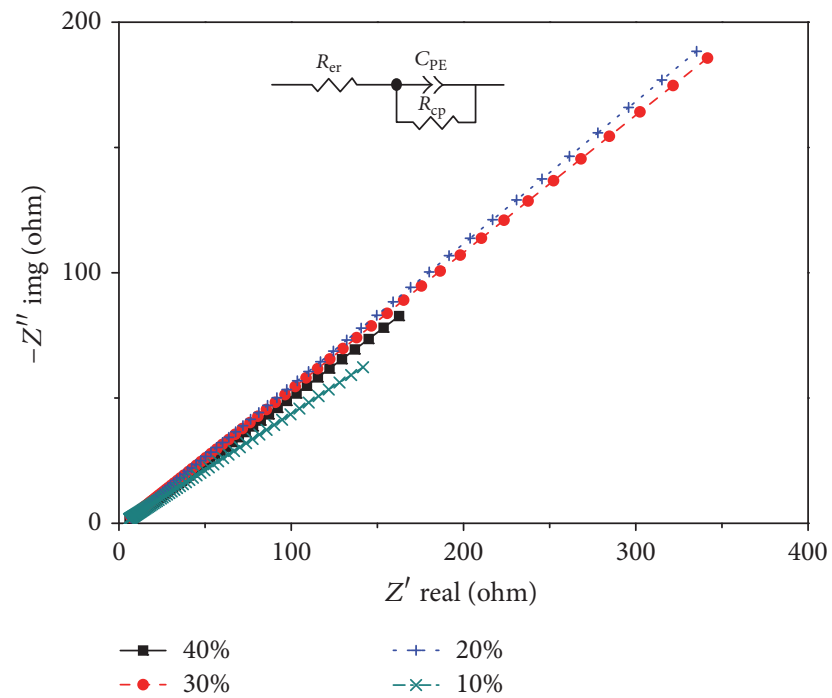

FIGURE 9: Nyquist plot of epoxy-lacquer based coatings with different $\mathrm{Al}$ mass fraction. Internal illustration was the equivalent circuit.

more inhomogeneous, and thus the porosity was increased. The experimental results showed that when the $\mathrm{Al}$ mass fraction was controlled at $30 \%$, the epoxy-lacquer based coating had good corrosion resistance and durability, which had more positive $E_{\text {corr }}$, higher $R_{\mathrm{P}}$, lower $I_{\text {corr }}$, and lower porosity.

Figure 9 showed the EIS of epoxy-lacquer based coatings with different $\mathrm{Al}$ mass fraction and the equivalent circuit. $R_{\text {er }}$ represents the resistance of electrolyte, $C_{\mathrm{PE}}$ represents the phase element related to the capacitance of epoxy-lacquer based coatings, and $R_{\mathrm{cp}}$ represents the pore resistance of epoxy-lacquer based coatings. The parameters of EIS were presented in Table 4.

As can be seen from Table $4, R_{\mathrm{er}}$ has always been a small value for a given electrolyte. $R_{\mathrm{cp}}$ of epoxy-lacquer based coatings with $\mathrm{Al}$ mass fraction of $30 \%$ is $3.225 \times 10^{11}$, much higher than that of $\mathrm{Al}$ mass fraction of $10 \%$. The higher value of $R_{\mathrm{cp}}$ and lower value of $C_{\mathrm{c}}$ showed good corrosion resistance of epoxy-lacquer based coatings with $\mathrm{Al}$ mass fraction of $30 \%$ [25].

The change trend of the IR emissivity of the epoxylacquer based coatings with different $\mathrm{Al}$ mass fraction in the corrosive medium was used for the evaluation of stability. The smaller the variation of IR emissivity is, the better corrosion

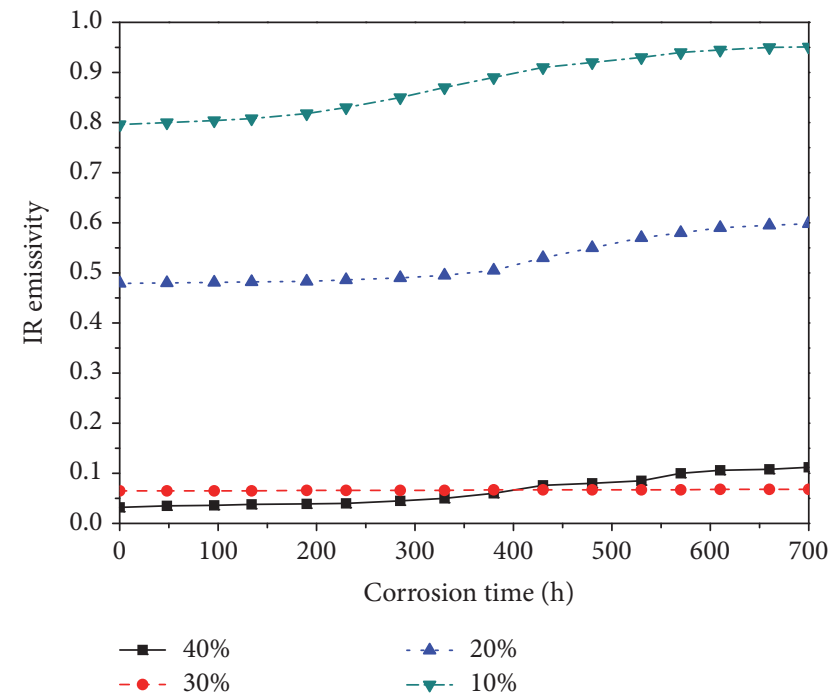

FIGURE 10: The change of IR emissivity of epoxy-lacquer based coatings with different $\mathrm{Al}$ mass fraction with corrosion time.

resistance and the stability of the coating are [26]. The change trend of IR emissivity of the epoxy-lacquer based coatings with different $\mathrm{Al}$ mass fraction in $3.5 \% \mathrm{NaCl}$ solution was shown in Figure 10.

It can be seen that the IR emissivity of epoxy-lacquer based coatings with $\mathrm{Al}$ mass fraction of $30 \%$ was almost unchanged with the corrosion time, and the IR emissivity of the epoxy-lacquer based coatings with $\mathrm{Al}$ mass fraction of $20 \%$ and $40 \%$ increased slightly with increasing corrosion time. However, the IR emissivity of the epoxy-lacquer based coatings with $\mathrm{Al}$ mass fraction of $10 \%$ increased significantly from 0.796 to 0.951 in the corrosion time of $0-700 \mathrm{~h}$. It was apparent that the stability of epoxy-lacquer based coatings with $\mathrm{Al}$ mass fraction of $30 \%$ was the best.

3.5. Comparison of Epoxy-Lacquer Based Coating with PU Based Coating. The performance of epoxy-lacquer based coating was compared with that of the PU based coating $[7,23,27]$, as shown in Table 5 . The low IR emissivity of these coatings $(\sim 0.100)$ can be obtained when the mass fraction of filler is appropriate. The gloss of the epoxy-lacquer based coating was much lower than that of PU based coatings. The epoxy-lacquer based coating had better durability, lower porosity, and better mechanical properties compared with PU based coatings. 
TABle 5: Performance comparison of epoxy-lacquer with PU based coatings.

\begin{tabular}{|c|c|c|c|c|c|c|}
\hline Coating & Filler mass fraction (\%) & Emissivity & Gloss (\%) & Adhesion (grade) & Impact resistance $(\mathrm{kg} \cdot \mathrm{cm})$ & $P$ \\
\hline Epoxy-lacquer/Al & 30 & 0.065 & 5.7 & 1 & 50 & $2.7 \times 10^{-7}$ \\
\hline $\mathrm{PU} / \mathrm{Cu}$ & 50 & 0.100 & 45.2 & 3 & 20 & - \\
\hline PU/(ball-milled Ag-Cu) & 50 & 0.129 & 35.6 & 3 & 20 & $3.2 \times 10^{-3}$ \\
\hline Epoxy-PU/bronze & 40 & 0.069 & 35.4 & 1 & 50 & $1.0 \times 10^{-4}$ \\
\hline $\mathrm{PU} / \mathrm{Al}$ & 40 & 0.068 & 38.3 & 1 & 40 & $8.6 \times 10^{-6}$ \\
\hline
\end{tabular}

\section{Conclusions}

With Al mass fraction decreasing from $40 \%$ to $10 \%$, IR emissivity of the epoxy-lacquer based coating was raised from 0.032 to 0.796 , and the gloss of the epoxy-lacquer based coating increased from $4.8 \%$ to $51.7 \%$. The adhesion and impact resistance first increased and then decreased with decreasing $\mathrm{Al}$ mass fraction. When the $\mathrm{Al}$ mass fraction is $30 \%$, the coating had the best adhesion and impact strength. They were grade 1 and $50 \mathrm{Kg} \cdot \mathrm{cm}$, respectively. In addition, potentiodynamic polarization and EIS showed that the corrosion resistance of the epoxy-lacquer based composite coating increased when the $\mathrm{Al}$ mass fraction was decreased from $40 \%$ to $30 \%$. When the $\mathrm{Al}$ mass fraction was less than $30 \%$, the corrosion resistance of the coating decreased. The stability of epoxy-lacquer based coatings with $\mathrm{Al}$ mass fraction of $30 \%$ was the best. Investigation results showed that when the $\mathrm{Al}$ mass fraction was 30\%, the epoxy-lacquer based coating had lower gloss and IR emissivity, more excellent mechanical properties, and higher durability compared to PU based coatings (PU/Al coating). Using epoxy-lacquer and $\mathrm{Al}$ to produce coatings will open up a new method for novel functional coatings.

\section{Conflicts of Interest}

The authors declare that there are no financial conflicts of interest.

\section{Acknowledgments}

This project is supported by the Jiangsu Basic Research Program (BK20150887), Jiangsu University Natural Science Research Project (14KJB220007), Youth Science and Technology Innovation Fund of Nanjing Forestry University (CX2016018), Priority Academic Program Development of Jiangsu Higher Education Institutions (PAPD), and China Postdoctoral Science Foundation (2015M570444).

\section{References}

[1] Y. Yang, C. Sun, Y. Zhou, T. Wang, and Y. Zhang, "Optically active polyurethane based on tyrosine: Synthesis, characterization and study of hydrogen bonding," Polymer Journal, vol. 48, no. 7, pp. 807-812, 2016.

[2] C. Loka, K. R. Park, and K.-S. Lee, "Multi-functional $\mathrm{TiO}_{2} / \mathrm{Si} /$ $\mathrm{Ag}(\mathrm{Cr}) / \mathrm{TiN}_{x}$ coatings for low-emissivity and hydrophilic applications," Applied Surface Science, vol. 363, pp. 439-444, 2016.
[3] Y. Yu, S. Sun, Y. Yu, L. Mi, Y. Cao, and L. Song, "The temperature-dependent electricity and emissivity properties of $\mathrm{La} 0.67 \mathrm{Ca}_{0.33-x} \mathrm{Sr}_{x} \mathrm{MnO}_{3}$ compounds," Journal of Alloys and Compounds, vol. 682, pp. 579-583, 2016.

[4] M. M. S. Al Bosta and K.-J. Ma, "Influence of electrolyte temperature on properties and infrared emissivity of MAO ceramic coating on 6061 aluminum alloy," Infrared Physics and Technology, vol. 67, pp. 63-72, 2014.

[5] M. J. Miller and J. Wang, "Multilayer ITO/ $/ \mathrm{VO}_{2} / \mathrm{TiO}_{2}$ thin films for control of solar and thermal spectra," Solar Energy Materials and Solar Cells, vol. 154, pp. 88-93, 2016.

[6] X. Huang, W. Rao, Y. Chen et al., "Infrared emitting properties and environmental stability performance of aluminum/polymer composite coating," Journal of Materials Science: Materials in Electronics, vol. 27, no. 6, pp. 5543-5548, 2016.

[7] X. Yan and G. Xu, "Corrosion and mechanical properties of polyurethane/Al composite coatings with low infrared emissivity," Journal of Alloys and Compounds, vol. 491, no. 1-2, pp. 649653, 2010.

[8] L. Yuan, J. Hu, X. Weng, Q. Zhang, and L. Deng, "Galvanic displacement synthesis of $\mathrm{Al} / \mathrm{Ni}$ core-shell pigments and their low infrared emissivity application," Journal of Alloys and Compounds, vol. 670, pp. 275-280, 2016.

[9] J. Liu, K. Wang, L. Lin et al., "Synthesis and property of fluorinated polyimides with double bond end groups for UVcured coating," Progress in Organic Coatings, vol. 99, pp. 103109, 2016.

[10] W.-M. Tan, L.-F. Wang, F. Yu et al., "Preparation and characterization of a greenish yellow lackluster coating with low infrared emissivity based on Prussian blue modified aluminum," Progress in Organic Coatings, vol. 77, no. 7, pp. 11631168, 2014.

[11] G. Wu and D. Yu, "Preparation and characterization of a new low infrared-emissivity coating based on modified aluminum," Progress in Organic Coatings, vol. 76, no. 1, pp. 107-112, 2013.

[12] G. Melia, J. Moghal, C. Hicks, M. Oubaha, D. McCormack, and B. Duffy, "Investigation of the mechanical and thermal fatigue properties of hybrid sol-gel coatings applied to AA2024 substrates," Journal of Coatings Technology Research, vol. 13, no. 6, pp. 1083-1094, 2016.

[13] X.-M. Ma, R. Lu, and T. Miyakoshi, "Application of pyrolysis gas chromatography/mass spectrometry in lacquer research: a review," Polymers, vol. 6, no. 1, pp. 132-144, 2014.

[14] H. Watanabe, A. Fujimoto, and A. Takahara, "Surface texturing of natural 'urushi' thermosetting polymer thin films," Polymer Journal, vol. 46, no. 4, pp. 216-219, 2014.

[15] S. Kanehashi, H. Oyagi, R. Lu, and T. Miyakoshi, "Development of bio-based hybrid resin, from natural lacquer," Progress in Organic Coatings, vol. 77, no. 1, pp. 24-29, 2014. 
[16] Y. Shi and G. Wang, "The novel silicon-containing epoxy/PEPA phosphate flame retardant for transparent intumescent fire resistant coating," Applied Surface Science, vol. 385, pp. 453-463, 2016.

[17] J. Li, M. Ge, Y. Zhu, and Z. Chen, "Morphology and photoluminescence properties of phenolic epoxy resin coating on KH550-modified SrAl2O4: $\mathrm{Eu}^{2+}, \mathrm{Dy}^{3+}$ powder in the presence of triarylsulfonium hexafluoroantimonate," Journal of Coatings Technology and Research, vol. 13, no. 6, pp. 1075-1082, 2016.

[18] S. Naghdi, B. Jaleh, and A. Ehsani, "Electrophoretic deposition of graphene oxide on aluminum: characterization, low thermal annealing, surface and anticorrosive properties," Bulletin of the Chemical Society of Japan, vol. 88, no. 5, pp. 722-728, 2015.

[19] H. S. Bhat and B. Osting, "Kirchhoff's laws as a finite volume method for the planar Maxwell equations," IEEE Transactions on Antennas and Propagation, vol. 59, no. 10, pp. 3772-3779, 2011.

[20] J. Yang, J. Deng, J. Zhu, W. Liu, M. Zhou, and D. Li, “Thermal polymerization of lacquer sap and its effects on the properties of lacquer film," Progress in Organic Coatings, vol. 94, pp. 41-48, 2016.

[21] S. Zhao, H. Y. Chang, S. Chen, J. Cui, and Y. H. Yan, "Highperformance and multifunctional epoxy composites filled with epoxide-functionalized grapheme," European Polymer Journal, vol. 84, pp. 300-312, 2016.

[22] X. Tao, J. Liu, X. Xu et al., "Comparative study of MoSi2borosilicate glass coatings on fibrous ceramics prepared by insitu reaction method and two-step method," Journal of Alloys and Compounds, vol. 684, pp. 488-495, 2016.

[23] X. Yan and G. Xu, "Influence of silane coupling agent on corrosion-resistant property in low infrared emissivity $\mathrm{Cu}$ /polyurethane coating," Progress in Organic Coatings, vol. 73, no. 2-3, pp. 232-238, 2012.

[24] M. Mo, W. Zhao, Z. Chen et al., "Excellent tribological and anticorrosion performance of polyurethane composite coatings reinforced with functionalized graphene and graphene oxide nanosheets," RSC Advances, vol. 5, no. 70, pp. 56486-56497, 2015.

[25] Z. Wen, Y. Bai, J. Yang, and J. Huang, "Corrosion resistance of vacuum re-melted Ni60-NiCrMoY alloy coatings," Journal of Alloys and Compounds, vol. 711, pp. 659-669, 2017.

[26] H. Yu, G. Xu, X. Shen, X. Yan, C. Hu, and Y. Wang, "Corrosion resistance and infrared emissivity properties of EPDM (EPDMg-MAH) film on low infrared emissivity $\mathrm{PU} / \mathrm{Cu}$ coating," Electrochimica Acta, vol. 55, no. 5, pp. 1843-1847, 2010.

[27] X. Yan and G. Xu, "Effect of surface modification of $\mathrm{Cu}$ with Ag by ball-milling on the corrosion resistance of low infrared emissivity coating," Materials Science and Engineering B: SolidState Materials for Advanced Technology, vol. 166, no. 2, pp. 152157, 2010. 

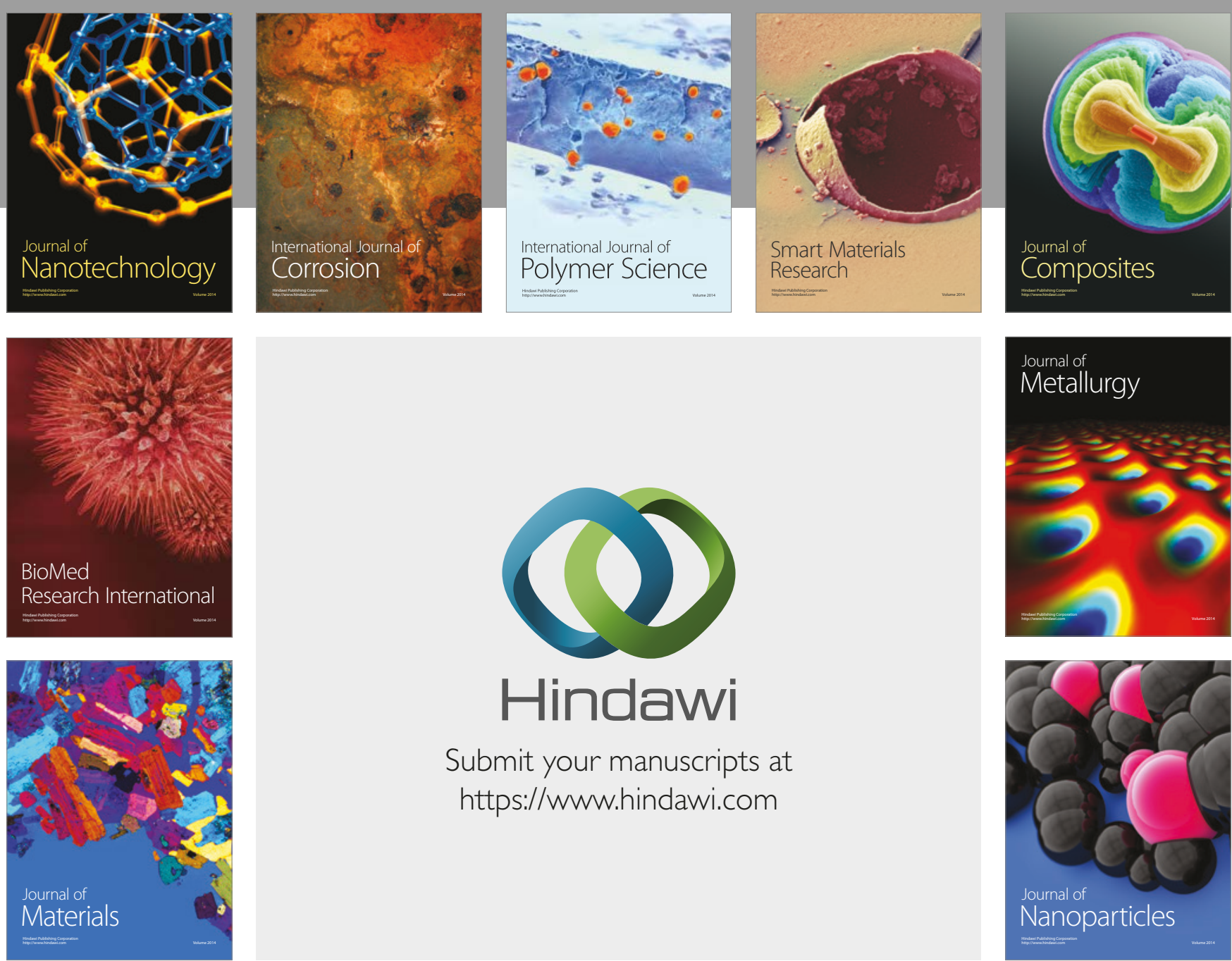

\section{Hindawi}

Submit your manuscripts at

https://www.hindawi.com
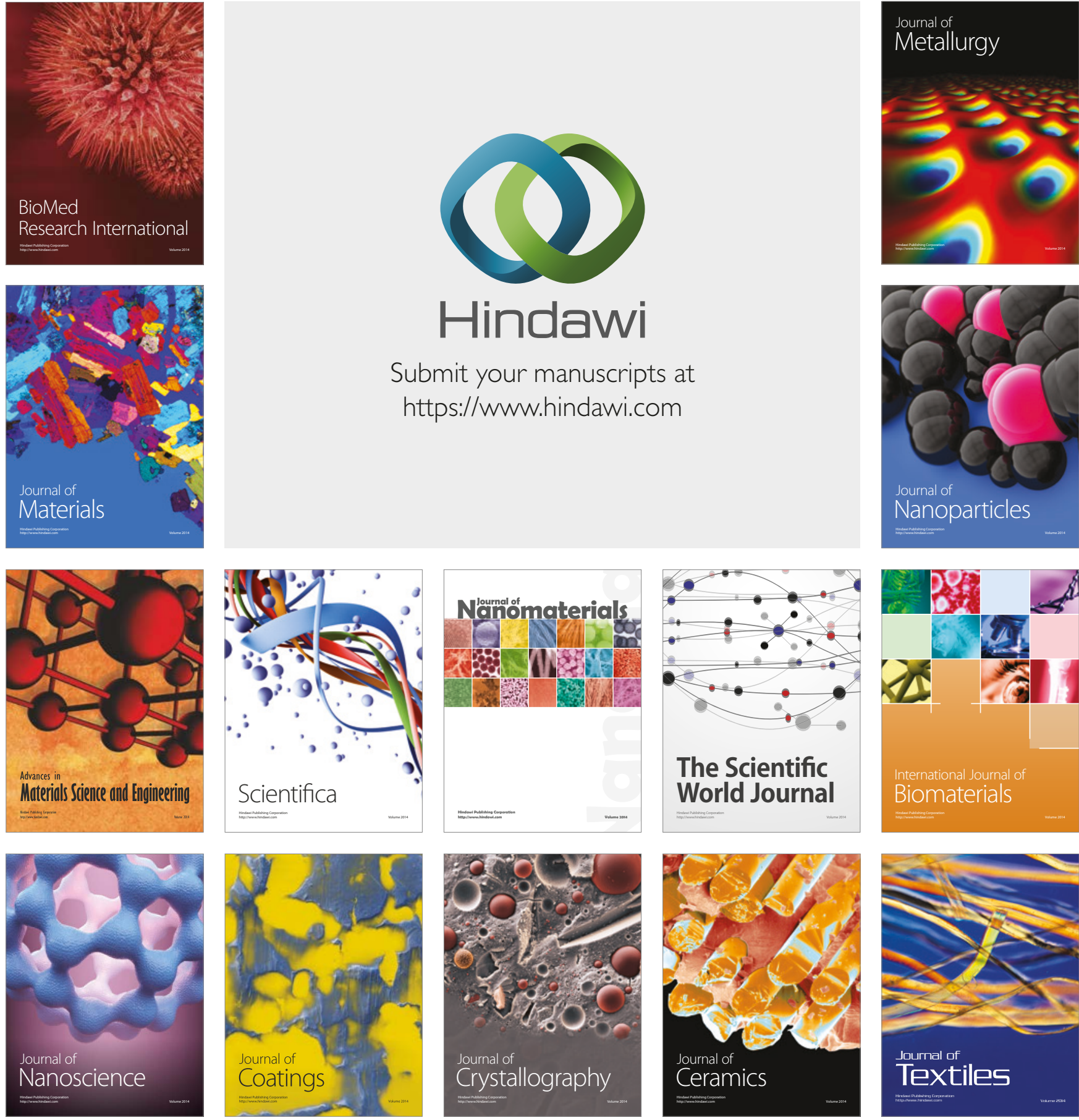

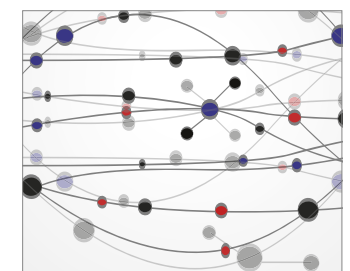

The Scientific World Journal
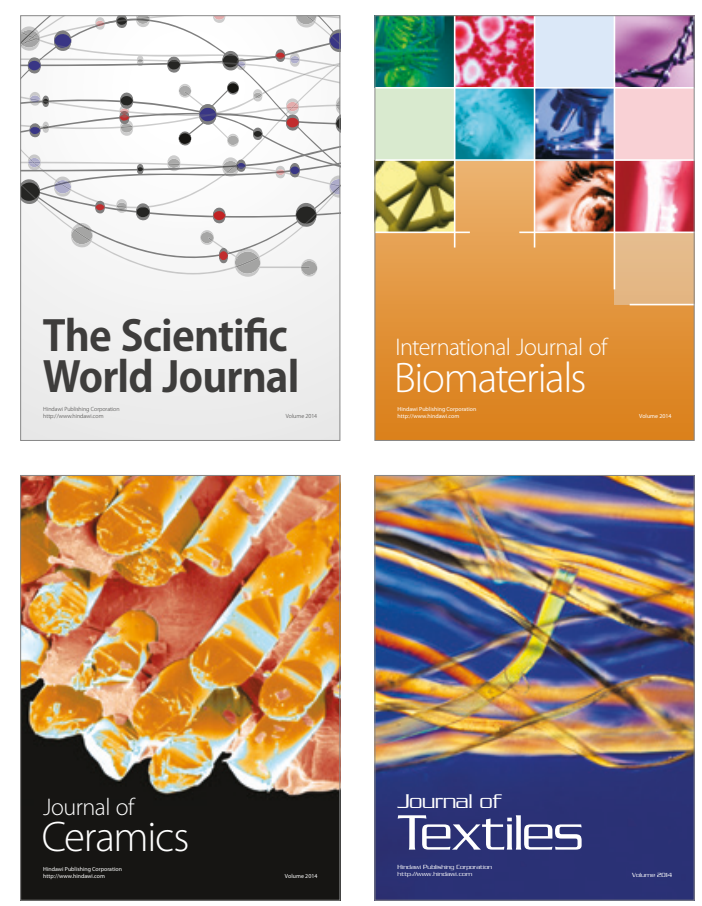